\title{
Evasión e hiperrealidad en The Universal Baseball Association, Inc., J. Henry Waugh, Proprietor
}

Recibido: $15 / 12 / 2010$

\author{
Esther CLAUDIO MORENO \\ Universidad Complutense de Madrid \\ soyesthercilla@gmail.com
}

Aceptado: 10/03/2011

\section{RESUMEN}

Este artículo ofrece un acercamiento sociológico a la obra de Robert Coover The Universal Baseball Association, Inc., J. Henry Waugh, Proprietor basado en el pensamiento de Jean Baudrillard. Consideramos a Henry Waugh, el protagonista de dicha novela, el arquetipo del sujeto postmoderno baudrillardiano y su liga de baseball simulada una representación metafórica de la hiperrealidad. Partiendo de estas premisas, trataremos de analizar las formas de evasión y encuentro en una sociedad asolada por la imaginería mediática y los mundos virtuales.

Palabras clave: hiperrealidad, evasión, simulacro, ontología, postmodernidad, solipsismo.

$$
\begin{gathered}
\text { Escapism and hyperreality in The Universal Baseball Association, Inc., J. } \\
\text { Henry Waugh, Proprietor }
\end{gathered}
$$

\begin{abstract}
In this article we intend to offer a sociological approach to Robert Coover's The Universal Baseball Association, Inc., J. Henry Waugh, Proprietor based on Jean Baudrillard's thinking. We consider Henry Waugh, the novel's protagonist, the archtype of the baudrillardian postmodern subject and his Universal Baseball Association as a metaphorical representation of hyperreality. Given these premises, we will analyze the escape and encounter ways in a society inundated by media imagery and virtual worlds.
\end{abstract}

Keywords: hyperreality, escapism, simulacrum, ontology, postmodernity, solipsism.

SUMARIO: 1.Introducción. 2. Reglas del Juego. 3. Proyección del simulacro. 4. Vías de escape: la hiperrealidad como forma de vida. 5. Conclusión.

\section{INTRODUCCIÓN}

Baudrillard define la posmodernidad como la era del simulacro, de la sustitución de lo real por los signos de lo real. Basándose en Saussure, afirma que el orden entre significante y significado ha sido invertido en la sociedad postmoderna de manera que el significante, el referente, el icono, precede al significado, lo referido, la base real 
del signo. Así, los simulacros dan lugar a un mundo independiente y autosuficiente, lo que Baudrillard denomina "hiperrealidad" y Henry Waugh, el protagonista de la novela The Universal Baseball Association, Inc., J. Henry Waugh, Prop. de Robert Coover, materializa en su juego de baseball imaginario. Henry, un oficinista fracasado, se aisla del mundo en una vida simulada, en este caso en un juego de baseball, que "re-crea" su existencia y funciona como vía de escape de una vida gris y monótona. Al llevar este mundo imaginario hasta el extremo, Henry se convierte en el arquetipo de la filosofía pesimista y a veces exagerada de Baudrillard. La hiperrealidad es el orden de una sociedad calificada por muchos como hedonista, narcisista y pesimista, donde lo inexistente es real porque la ficción parece ser la única realidad posible para personajes como Henry que necesitan rodearse de una fantasía solipsista para mediar con el exterior. Tradicionalmente considerada una novela sobre la creatividad y la desmitificación, nosotros trataremos de ofrecer una interpretación sobre los límites entre la realidad y la ficción en la era de la realidad virtual.

En la hiperrealidad del mundo extra-textual, los referentes no sólo provienen de sistemas de creencia obsoletos, sino también del sistema de producción y consumo en el que se basa el capitalismo. Henry Waugh puede no estar afectado en exceso por el consumismo, pero se ve abrumado por la simulación del baseball de la misma manera que el ciudadano común se ve inmerso en las diferentes simulaciones que la publicidad, la televisión, los medios y otras formas de comunicación producen. Los iconos, los referentes y los significantes vacíos se multiplican y parecen poseer el potencial para sustituir la realidad como el juego de baseball sustituye la vida de Henry. A lo largo de la novela asistimos a la recreación de un mundo hiperreal, la liga de Baseball Universal, donde los signos de lo real sustituyen lo que un día representaron hasta que un día, de repente, inundan la realidad. En el enigmático último capítulo de la novela, Henry desaparece y los únicos personajes que permanecen son los descendientes de sus jugadores cien años después. Como el sujeto postmoderno, ellos no encuentran significado alguno a sus vidas porque lo único que tienen son los signos, los restos, de lo que el juego significó en origen. "Cuando lo real ya no es lo que era, la nostalgia cobra todo su sentido. Pujanza de los mitos del origen y de los signos de la realidad" $(19)^{1}$. Los mitos son simulaciones en sí mismos que sobreviven a día de hoy como la UBA lo hace para los descendientes de los jugadores, como un paisaje vacío de referencias. Tal es la situación que presenta la novela cuando la realidad de Henry Waugh queda literalmente eliminada por la de la liga de baseball imaginaria.

El giro hacia lo fantástico en este último capítulo de la novela cuestiona la ontología del mundo real. Como afirma Todorov, desde La Metamorfosis de Kafka la Fantasía ya no enfrenta lo real y lo irreal, sino dos realidades distintas. En The Universal Baseball Association..., así como en la mayoría de la producción

\footnotetext{
${ }^{1}$ Jean Baudrillard (2007). Cultura y Simulacro. Barcelona: Kairós.
} 
postmoderna, la ontología del mundo conocido se pone en entredicho cuando el universo imaginario adquiere agencia, cuando la fantasía y la realidad se entrecruzan. Sin embargo, no se trata sólo de una cuestión de elucidar la naturaleza del entorno, sino también del ser humano. La sustitución del mundo real por uno virtual implica un distanciamiento del "otro" físico que, a veces, hace preferir el ser imaginario al ser de carne y hueso. El otro se convierte en proyección, en la imagen ubicua e instantánea de uno mismo, gracias al acortamiento espacio-temporal que los medios han hecho posible. Al quedar reducido a una imagen, el otro se convierte en el doble del sujeto que lo percibe y pasa a formar parte de su solipsismo. Los otros, virtualmente, ya no existen porque la tecnología los transforma en figuras phantasmáticas. Son nuestros jugadores de baseball y el mundo nuestra UBA.

En este artículo desarrollaremos éstas y otras ideas, relacionando la obra de Coover con el concepto baudrillardiano de hiperrealidad en un esfuerzo por comprender los nuevos mecanismos de evasión en una sociedad cada vez más artificial, al tiempo que ofreceremos un nuevo enfoque de la producción cultural actual.

\section{REGLAS DEL JUEGO}

Victor I. Stoichita, en su obra sobre la historia del simulacro, define este fenómeno como "la imagen que parece poseer una existencia propia" $(11)^{2}$. Esto es exactamente lo que ocurre con el juego de baseball de Henry, es un sistema de seres "imaginarios" (i.e. imágenes mentales) que terminan por hacerse realidad. Los jugadores comienzan como objetos fantasmáticos lacanianos para Henry, como sustitutos de todo aquello que anhela en la vida (cariño, reconocimiento, poder, etc.) y, a medida que su locura progresa, adquieren mayor protagonismo hasta que, en el último capítulo, sólo ellos tienen voz y su creador desaparece por completo. Los personajes que en un principio son entes inanimados parecen finalmente poseer "una existencia propia", y el juego de baseball pasa de la simple mímesis (copia del baseball auténtico) al simulacro (la copia que rebasa sus límites y se hace realidad).

Desde el principio, el juego es más real que la propia realidad, es hiperreal. Es parte de la vida de Henry como las personas que le rodean o el bar de la esquina y, a cada instante, nuestro protagonista puede sentir la emoción de los partidos, ya sea andando por la calle, en el trabajo o subiendo las escaleras: "Mounting the stairs, Henry heard the roar of the crowd, saw them take their seats. Bowlegged old Maggie Everts trundled out of the Haymaker dugout to replace Hill."'(6) ${ }^{3}$. El juego es fuente

\footnotetext{
${ }^{2}$ Victor I Stoichita (2006). Simulacros: El efecto Pigmalión: de Ovidio a Hitchcock. Madrid : Siruela, D.L.

3 A partir de ahora siempre citaremos por: Robert Coover (1971). The Universal Baseball Association, Inc., J. Henry Waugh, Prop. New York: Plume.
} 
de emociones para Henry, quien llena su vida con los sentimientos y sensaciones que su rutina diaria no le ofrece:

Henry ... felt the boy's inner excitement, shook his head in amazement at his outer serenity. "Nothing like this before." Yes, there was a soft murmur pulsing through the stands: nothing like it, electrifying, new, a new thing, happening here and now! ${ }^{4}(11)$.

En efecto, el juego tiene lugar "aquí y ahora" porque traspasa las fronteras del mero entretenimiento. Estas palabras se refieren además al clímax de la liga, que tiene lugar al poco de comenzar la novela, y que cambia para siempre la vida de Henry. Cuando parecía que el aburrimiento se hacía presa del juego como de todo lo demás en la vida del protagonista, un evento sensacional tiene lugar. El rookie (máximo lanzador) de la liga, Damon Rutherford, lanza una bola imposible y se anota un juego perfecto que inyecta a Henry una energía y un optimismo desconocidos hasta entonces. Tras una experiencia así, comienza a involucrarse más en su pasatiempo, aunque al mismo tiempo es consciente de que se está obsesionando con él, "and he knew that total one-sided participation in the league would soon grow even more oppresive than his job at Dunkelmann, Zauber \& Zifferblatt" (141).

Existe una serie de reglas cuidadosamente detalladas que el propio Henry ha establecido. Los partidos se juegan con un tablero y tres dados. A cada combinación de dados les corresponde una jugada teniendo en cuenta una serie de variables en las que no falta detalle: antigüedad del jugador, edad, cansancio, estado anímico, historial, etc. Las puntuaciones, estadísticas, y demás cifras han sido registradas al milímetro en un cuaderno y cuando comienza la novela nos encontramos en la temporada LVI. En el siguiente partido, aunque Damon debería descansar, Henry lo elige para lanzar y lo peor que podía suceder se hace realidad. Waugh saca tres 1 consecutivos en tres tiradas, la combinación mortal, según la cual el bateador debe ser golpeado mortalmente por una "beanball" (lanzamiento ofensivo directo al bateador). Damon muere y Henry, que lo quería como al hijo que nunca tuvo, cae en picado, sufre una depresión que le lleva a abandonar el trabajo y la escasa vida social de la que gozaba para hundirse por completo en su simulación.

Antes de este trágico momento, Henry ya había empezado a sentir cómo el pasatiempo copaba toda su vida. Incluso actúa de filtro entre su entorno y él, interpretando cualquier suceso en términos deportivos:

The rain tumbled like gentle applause on his umbrella. Under it he walked, skirting the puddles, dry in the deluge, as though glassed in under a peaked black dome. Hunchedup cars pushed through the streets like angry defeated ballplayers jockeying through crowds on their way to the showers...A policeman...jerk[ed] his arms like a base coach urging a runner on. (46)

\footnotetext{
${ }^{4}$ La cursiva es mía
} 
En este momento, Henry abandona el símil y la metáfora "for a kind of hallucinatory equivalence of real and fantasized people and things" (Gordon, 36) . Los límites entre fantasía y realidad se desdibujan y con ello el lugar al que se veía confinado el juego. Le afecta incluso en el trabajo y nota que cuanto mejor hace los cálculos para su juego, más errores comete en la oficina ${ }^{6}$. Pero el momento decisivo llega con la muerte de Damon, suceso que desata la obsesión de Henry y pasa a ser más importante que su propia vida. Cuando la UBA traspasa las fronteras del entretenimiento, cuando traspasa las fronteras físicas del tablero para instalarse en la mente de Henry y desde ahí a inundar su realidad, lo que era un simple objeto, copia de un deporte real, se transforma no sólo en obsesión, sino en simulacro. Éste es el momento en que algo inanimado adquiere "una existencia propia". El juego, como la estatua de Pigmalión (mito fundacional del simulacro ${ }^{7}$ ), rompe el molde y comienza a vivir.

Desde la muerte de Damon, Henry no levanta cabeza, y para consolarse se hunde mucho más en su querido pasatiempo. A partir de entonces, las alucinaciones son casi continuas (clara indicación de que Waugh ha perdido la capacidad para distinguir la realidad de la ficción). Compra flores para Damon y hace un simulacro de funeral, al que imagina que acuden todos los compañeros, cantan himnos y llevan a cabo una serie de ceremonias. Henry pasa la noche en vela inmerso en su mundo y le resulta cada vez más difícil encarar la vuelta al trabajo y soportar a su jefe, "the old man":

He looked at his watch: still more than an hour before he had to confront the old man. What could he tell him? ... It was autumn, but Henry felt plunged into the deepest of winters. But no, it was the middle of a baseball season, remember? Green fields and hot suns and shirtsleeved fanatics out on the bleaching boards, last to give it up and go home: he turned back to the table. (129)

A partir de este momento, el lenguaje es cada vez más hermético, más obsesivo, como la mente de Henry. Las incursiones en el mundo de los jugadores aumentan y se alargan al tiempo que dejamos de tener noticias del personaje, excepto que sufre una depresión, deja el trabajo y desaparece de la narración.

En un final brillante y significativo como pocos, la novela da un giro y la realidad con la que nos habíamos familiarizado hasta entonces, la de Henry Waugh,

\footnotetext{
${ }^{5}$ Lois Gordon (1983). Robert Coover: the universal fictionmaking process. Carbondale : Southern Illinois University Press, (V. n.5, p. 171).

6 "Henry had to admit that the more carefully he figured the percentages and tabulated the records of his Association, the more mistakes he seemed to make here at work", 42

${ }^{7}$ Víctor I. Stoichita, en su libro Simulacros...: realiza un exhaustivo estudio de la historia del simulacro en el arte. A través de este análisis sitúa a Pigmalión como el mito fundador del simulacro en la cultura occidental: "La historia del escultor chipriota del que los dioses se compadecieron por haberse enamorado tan perdidamente de su obra, y en un rasgo de magnanimidad concedieron vida a su estatua, es la primera gran historia del simulacro de la cultura occidental.". Así lo consideraremos nosotros también en este trabajo.
} 
desaparece por completo. En su lugar, nos encontramos frente a los descendientes de la UBA cien años después. No sabemos nada más: nada sobre Henry, nada sobre las temporadas pasadas y nada sobre los propios jugadores -si son o no reales, si son fruto de la locura de su creador o si es sólo un juego más. Este factor multiplica las interpretaciones y deja abierta la obra a numerosos acercamientos críticos. En nuestro trabajo, tomando el juego como un simulacro, éste es el momento en que "la imagen" adquiere "una existencia propia", no sólo porque los jugadores son los únicos en tener voz aquí, sino porque se plantean la existencia de un creador, lo que destruye la superioridad del nivel diegético en que se inserta su relato y los dota de vida. ¿Qué ocurre cuando estos personajes comienzan a reflexionar, a concebir un nivel superior, en este caso un "creador"? Rompen la barrera impuesta por la lógica del relato para cuestionar no sólo su mundo, su "realidad" sino también la de nosotros como lectores $^{8}$. En este momento, los personajes existen, adquieren agencia y miran a su creador a los ojos.

La imagen que cobra vida es un simulacro según la definición de Stoichita. Para Baudrillard, además, es una imagen autónoma que ya no guarda relación con ningún tipo de realidad originaria ${ }^{9}$, dejando de ser un reflejo para pasar a sustituir por completo aquello que mimetizaba. En el último capítulo de la novela, los personajes se encuentran en la fase final de la imagen baudrillardiana, son un simulacro que ya no guarda relación con el mundo del que dependían. Por una parte, Henry, lo único pretendidamente "real" en toda esta historia, ha desaparecido y, por otra, ellos mismos manifiestan una completa desvinculación con lo que fue la UBA y el propio baseball, lo que un día fue su "realidad":

Beyond each game, he sees another, and yet another, in endless and hopeless succession. He hits a ground ball to third, is thrown out. Or he beats the throw. What difference, in the terror of eternity, does it make? (238)

A diferencia de Damon Rutherford y sus antecesores, ellos no entienden el juego ni lo disfrutan. Sólo siguen adelante, repitiendo el duelo Damon-Casey anualmente, sin comprender por qué lo hacen o por qué el mundo que conocen es como es. El simulacro es "una suplantación de lo real por los signos de lo real". Los descendientes

\footnotetext{
${ }^{8}$ Es decir, siguiendo la estructura de las cajas chinas, cada uno de los niveles narrativos establece su primacía básicamente porque los personajes que en él intervienen pueden concebir seres y mundos ficticios en relatos inferiores, pero los personajes de estos últimos no conocen lo que sucede en el relato en que se enmarcan, el relato "superior". Es una estructura asimétrica en la que, como explica Eco, el mundo "ficticio" es accesible al mundo real pero el mundo real no es accesible al mundo ficticio. (v. Eco, Lector in Fabula, 241) Si el proceso se invierte se crea un trampantojo que dota de ontología al mundo supuestamente "ficticio".

${ }^{9}$ Baudrillard establece cuatro fases para la imagen: la imagen como reflejo de una realidad; como enmascaramiento de una realidad profunda; como enmascaramiento de la ausencia de esta realidad; y como simulacro que ya no tiene nada que ver con ningún tipo de realidad (v. Baudrillard, Cultura y Simulacro (13-18).
} 
suplantan a los grandes jugadores, el ritual al juego y los signos de lo real a la realidad. Este distanciamiento temporal despoja a la liga de significado y deja sólo las señales de la misma, unas señas vacías, un simulacro del mundo.

La desaparición del mundo real (entendido como el nivel ontológico correspondiente a la vida de Henry) origina un terrible vacío existencial en los jugadores. Uno de ellos, Paul Trench, lo expresa así:

He stares at the sky, beyond which is more sky, overwhelming in its enormity. He, Paul Trench, is utterly absorbed in it, entirely disappears, is Paul Trench no longer, is nothing at all: so why does he even walk up there? Why does he swing? Why does he run? Why does he suffer when out and rejoice when safe? Each day: the dread...He wants to quit - but what does he mean, "quit"? The game? Life? Could you separate them? (238)

Ni su papel como jugadores ni el juego en sí tienen ya sentido. Se han convertido en los significantes sin significado que según Baudrillard caracterizan a la postmodernidad. Si antes el significado precedía al significante, en la sociedad contemporánea este orden se ha invertido de tal modo que el significante precede aquello que designa.

A falta de un creador que dirija el juego, se aferran al único acontecimiento que parece haber tenido repercusión en la UBA y lo convierten en mito, el duelo DamonCasey. En este duelo, los jugadores se disfrazan de los protagonistas del incidente, actúan como ellos, son ellos ${ }^{10}$, y el auténtico juego, la liga de baseball, se paraliza ese día para que su caricatura la suplante. Todos los miembros de la UBA depositan su fe en esta ceremonia que les hace sentir más cerca de una edad dorada con la que sueñan pero que jamás existió. Son criaturas presas de un discurso prestado, de signos desligados de significante. El mito es la suplantación de lo real por los signos de lo real.

Con la desaparición de su creador, los jugadores viven la "muerte de Dios" propia del hombre moderno, la ausencia de un Dios conceptual que sea capaz de actuar como fuente de código moral o teología. Los mitos y rituales que llevan a cabo son simultáneamente su simulacro particular y residuos de épocas pasadas. En aquellos tiempos, estos rituales tenían sentido, pero ahora, tanto en el mundo actual como dentro de la UBA, los mitos son meros simulacros:

Signos que disimulan que no hay nada...inauguran la era ... en la que ya no hay un Dios que reconozca a los suyos, ni Juicio Final que separe lo falso de lo verdadero, lo real de su resurrección artificial, pues todo ha muerto y ha resucitado de antemano. (Baudrillard, 2007: 18)

\footnotetext{
10 "Trench and Ingram depart, under a cascade of cheers. But yes! It is really they! See how they go! Two still-young heroes of the golden past: miraculous transformation!" (The UBA, 237)
} 
Los mitos de épocas pasadas, como la religión, son simples residuos. Por eso, utilizarlo hoy día no tiene sentido, son piezas de un puzzle que no encaja y que lleva a pensar a los jugadores que "God exists and he is a nut" (233).

De hecho, las iniciales de Henry (JHW) son un acrónimo de Jahveh, como han señalado varios $\operatorname{críticos}^{11}$, y mediante sus acciones, se presenta en numerosas ocasiones como un Dios. Por ejemplo, él puede manipular el tiempo a placer, parando el juego o continuándolo. Sólo él tiene el don de la ubicuidad - está en todas partes y nada de la UBA le es ajeno. Pero, sin duda, el don divino por excelencia que Henry posee es la capacidad de dar vida con la palabra. Nombrar es un elemento fundamental en la creación (tanto religiosa como de la UBA):

Names had to be chosen, therefore, that could bear the whole weight of perpetuity. Brock Rutherford was a name like that; Horace Zifferblatt wasn't. Now, it was funny about names. All right, you bring a player up from the minors, call him A. Player A...gets a hit or he doesn't, gets his man out or he doesn't. Sounds simple. But call Player A "Sycamore Flynn" or "Melbourne Trench" and something starts to happen. He shrinks or grows, stretches out or puts on muscle. Throws mostly fast balls like Swanee Law or curves like Mickey Halifax. ... Strange. But name a man and you make him what he is. ...the basic stuff is already there. In the name. Or rather: in the naming. $(47-48)$

El hecho de dar nombre a sus personajes es lo que aleja a su juego de convertirse en una simple recopilación de datos (como lo es su trabajo de oficinista). Como todo pensador mítico, Henry considera que nombrar es dar vida y su poder es, sin duda, el de crear con palabras. El nombre otorga identidad a cada jugador y tiene algo de mágico, de omnipotente, que recuerda a la religión y a la mitología.

Como Dios, Henry puede incluso hacer milagros e intervenir en el juego. Sólo lo hace una vez, cuando Damon muere. Damon, su personaje predilecto y que recuerda en gran medida a Jesucristo, muere a manos del lanzador Casey. Henry no se puede contener y presa del dolor, en el siguiente juego, mata a Casey con sus propias manos dando la vuelta a los dados para que salga la combinación de 6-6-6 (el número del demonio) que significa la muerte instantánea. Ésta es la única vez que Waugh se salta las normas de su propio juego, lo que le servirá de punto de partida de su propia recuperación tras la depresión sufrida por la muerte de Damon. Al final, como sabemos, desaparece por completo del relato, igual que Dios desaparece de la Tierra una vez ha terminado su obra.

Los jugadores, imágenes que Henry proyecta de sí mismo, actúan como iconos de su persona. A veces son objetos fantasmáticos que le proporcionan lo que no puede obtener en su vida y el mundo de la UBA se convierte en "a personalized world where Henry finds friendship, love, and excitement" (McCaffery, 45). Pero la

${ }^{11}$ V. McCaffery, Gordon y McHale, entre otros. 
mayoría del tiempo, estas figuras actúan como "extensions of Henry's own personality"(45), proyecciones de sí mismo, distintas identidades que adopta a placer y que lo representan. Sus imágenes son él y él es sus imágenes. Según Baudrillard, las imágenes de Dios lo sustituyen con su poder de fascinación y sirven para ocultar el hecho de que nunca hubo dios alguno. Los jugadores, como los iconos religiosos, poseen "la todopoderosidad de los simulacros, la facultad de borrar a Dios de la conciencia de los hombres" (2007: 15), como ha ocurrido con Henry. Al fin y al cabo, "Dios no ha sido nunca,... sólo ha existido su simulacro..."(15) y Henry existirá sólo en tanto en cuanto sus criaturas quieran.

Ésta "is indeed the modern age, the post-Christian era, where belief is relative" (Gordon, 49). La relatividad y la duda se hacen presa de los jugadores quienes, al final de la narración, se erigen como personificaciones de las distintas actitudes hacia la vida y la experiencia del sujeto postmoderno. Nadie, ni en el juego ni en el mundo actual, entiende nada, nadie está seguro de nada, nadie tiene fe ni cree en la religión. Pero "If there is no God, Do the rules remain the same?" (Coover, 49), se pregunta Paul Trench. Parece que sí, porque en todo este maremagno de ideas y contradicciones, sólo una cosa sobrevive: la necesidad de mitología, la creación de simulacros.

Los rituales que la siguiente generación de jugadores lleva a cabo son su simulacro particular, un simulacro dentro de otro simulacro que proporciona ontología al segundo y a sus habitantes. Cuando los personajes comienzan a fundar su mundo de creencias abandonan su status de objetos (como peleles de Henry Waugh) para convertirse en agentes de su propio destino, en sujetos. Su mundo parece más real porque han creado una ficción que sirve de contraste con su realidad igual que la UBA sirvió de antítesis de la "realidad" de Henry. La creación de ficciones es lo que los hace humanos porque, como expresa uno de los jugadores, vivir sin "misterio" o "asombro" no merece la pena:

Cuss mocks the regime and everything else, but his mockery encapsulates him, cuts him off from any sense of wonder or mystery, makes life nothing more than getting by with the least pain possible, and somehow, to Paul Trench, such a life seems less than human. (240)

La ficción, los mitos, los rituales, y cualquier tipo de relato es lo que da sentido a la vida porque añade encanto a una existencia que se presenta banal y yerma. Sin ellos, el ser humano está perdido. Coover pretende en última instancia eliminar los discursos heredados a lo largo de generaciones porque su fin no es deshacerse de todo orden sino reconocer su naturaleza ficticia. Al relatar cómo una visión privada se convierte en mito, muestra cómo los seres humanos, no sólo Henry, sobreviven ritualizando sus propias experiencias. La reproducción de mitos por generaciones posteriores se deteriora porque éstos pierden fuerza y significado. Sin embargo, la necesidad de mitología no les abandona y crean nuevos órdenes para sustituir a los anteriores. En ocasiones, la renovación no resulta fácil pues son discursos eminentemente dogmáticos. Por esta razón, Coover parodia la religión, la historia, el mito, el deporte y 
cualquier sistema de creencias que pretende ser único y verdadero y los muestra como realmente son: meras ficciones inventadas para dar sentido a la vida. Este reconocimiento ofrece la posibilidad de deshacerse de los mismos con mayor libertad y reemplazarlos por ficciones nuevas más adecuadas. Si no, correremos la misma suerte que Henry - quedar atrapados en nuestra propia red de signos y permitir que éstos tomen el control de nuestras vidas.

El ser humano vive a través de ficciones, pero el potencial que albergan para adquirir una ontología propia parece amenazar la existencia misma del sujeto, especialmente en la era de las realidades paralelas y los mundos cibernéticos. De hecho, la conexión entre The UBA y la filosofía de Baudrillard reside en que Henry lleva al extremo su ficción y se convierte en el arquetipo dibujado por el pesimismo de la filosofía baudrillardiana. En su pensamiento, Baudrillard dibuja un presente y un futuro a veces exagerado en que absolutamente todos los objetos que rodean al sujeto toman su mundo. El sujeto desaparece y los objetos le suplantan a él y a su entorno. A grandes rasgos, la transformación del entorno y de la mentalidad que ha supuesto la llegada de la tecnología puede interpretarse de esta manera, pero no cabe duda de que es una interpretación extrema. Henry, creando su propia religión en forma de baseball de mesa y obsesionándose con ella, se convierte en un fanático, pero evadirse a través de la misma permitiendo e incluso deseando cambiar su vida de oficinista por la que podría tener en su mundo imaginario le convierten en el prototipo de individuo que según Baudrillard vive asolado por la intensidad de la imaginería mediática. La incapacidad de Henry para distinguir fantasía de realidad, y el enigmático final en que lo imaginario suplanta a lo real son la máxima expresión de una sociedad donde lo físico se hace virtual. Es "la necesidad de apoderarse del objeto en su más próxima cercanía, pero en imagen y, más aún, en copia, en reproducción”(Benjamin, 47) ${ }^{12}$, necesidad que se establece en la lógica de hacer de una estatua un ser vivo, como en Pigmalión. Las imágenes sustituyen lo representado y crean una red de simulacros que suplantan la realidad.

\section{PROYECCIÓN DEL SIMULACRO}

I hate reality. And, you know, unfortunately it's the only place where we can get a good steak dinner.

(Woody Allen)

El simulacro en torno al cual gira la obra nos acerca al género fantástico. En este punto, recordemos que existen dos formas de crear imágenes: "El arte de la copia (eikastiké) y el arte del simulacro (phantastiké)." Sin embargo, hasta hace muy poco

\footnotetext{
${ }^{12}$ Walter Benjamin (2003): La obra de arte en la época de su reproductibilidad técnica. México: Itaca.
} 
la imagen-eikon (la imagen-copia) se ve sometida a las leyes de la mímesis y atraviesa triunfalmente la historia de la representación occidental, mientras que el estatuto de la imagen-simulacro (phantasma) se caracterizará por ser fundamentalmente borroso y por estar cargado de oscuros poderes (Stoichita, 11) ${ }^{13}$.

Efectivamente, el simulacro ha estado siempre rodeado de un halo de magia y misterio, pues describe transformaciones asombrosas, como la de Pigmalión. Es el tropo por excelencia del género fantástico y, en cierto modo, se ha visto relegado a esta narrativa. Sin embargo, a día de hoy, el arte acoge con asiduidad obras basadas en la phantastiké como las composiciones holográficas, las digital beauties, o el hiperrealismo que reflejan este deseo por hacer de la imagen algo más que una copia. Es lógico, pues estamos asistiendo a una transformación del alrededor que parece más propia del género fantástico o de la ciencia ficción que de cualquier otro. Viajar por el espacio, hablar con personas a miles de kilómetros en tiempo real, acceder a una ingente cantidad de información desde casa de forma instantánea, experimentar la realidad virtual, volar... todos estos avances han transformado nuestra percepción del mundo y pareciera que lo imaginario hubiera cobrado vida. En la literatura, fantasía y postmodernismo se funden en autores como Coover porque, en la era del simulacro, éste se convierte en una forma de expresión especialmente significativa. La representación pretendidamente "veraz" del realismo no es capaz de representar una sociedad que, como explica Baudrillard, ya no es real sino simulada. Por tanto, si se ha de plasmar de algún modo, debe ser destruyendo los límites entre realidad y fantasía.

No obstante, también el género fantástico ha sufrido una transformación radical. La ausencia de "representación" en el arte ${ }^{14}$ está en la base, según Todorov, del cambio que el género fantástico sufrió desde La Metamorfosis de Kafka y la fusión entre este género y el postmodernismo. La capacidad de producir el asombro fantástico depende directamente de la capacidad para representar lo real, sobre todo del contraste entre lo posible y lo imposible, lo normal y lo paranormal. Pero ¿qué ocurre si, como afirma Baudrillard, la realidad desaparece? ${ }^{15}$ Sin lo real, lo fantástico ya no encuentra lugar. La banalidad del lenguaje y la ausencia de asombro ante lo sobrenatural que inundan La Metamorfosis supone, según Todorov, una ruptura del paradigma fantástico y The UBA lo adopta. En ausencia de realidad, de una vida propia para Henry y para sus jugadores, todos recurren a fantasías y ritos que llenen su mundo. Así, lo fantástico ya no se opone a lo real, sino que lo suplanta como una suerte de pseudorrealidad kafkiana.

13 Victor I. Stoichita (2006). Simulacros: El efecto Pigmalión: de Ovidio a Hitchcock, Madrid: Siruela, D.L.

${ }^{14}$ En el sentido tradicional de representación mimética o "realista".

${ }^{15}$ v. Jean Baudrillard (2000) El Crimen Perfecto. Barcelona: Anagrama. 
Además de la ausencia de parámetros que implica la desaparición de barreras entre lo real y lo irreal, postmodernismo y fantasía comparten una base ontológica. Como argumenta McHale, tomando de Rosemary Jackson el concepto de la fantasía como diálogo entre lo normal y lo paranormal, la fantasía es un género de "duda" ("hesitation") entre una realidad y otra. Si, con Kafka, desparece el contraste entre lo sobrenatural y lo real, la fantasía postmoderna se convierte en un diálogo entre dos niveles ontológicos posibles, dos realidades o dos irrealidades, como en The UBA. El diálogo en esta novela se desarrolla entre el mundo de Henry y el mundo de los jugadores. La ausencia de asombro y de lo sobrenatural es patente y la fantasía se presenta como una oportunidad para interrogar al mundo conocido. Ya no se trata de un diálogo entre lo natural y lo sobrenatural sino de uno entre dos realidades distintas que confluyen. Una ficción eminentemente ontológica que trata de dar respuesta a preguntas como "What happens ...when boundaries between worlds are violated?" (McHale, 10).

Lo que ocurre, si seguimos a Baudrillard, es que la realidad se transforma en hiperrealidad. "No se trata ya de imitación ni de reiteración, ni de parodia sino de una suplantación de lo real por los signos de lo real."(12) ${ }^{16}$ Se crea así una red de phantasmas que dan lugar a un mundo distinto del mundo representado, un mundo autónomo y autosuficiente, lo que Baudrillard llama la hiperrealidad y que Henry Waugh pone en práctica con su juego. Como en las réplicas exactas de los museos copia, los parques temáticos o la realidad virtual donde el yo pierde sus referentes y toma como real lo que es una copia o un constructo ficticio, Henry hace del juego su realidad. Cuando el juego le absorbe y lo envuelve, Waugh pierde sus referentes y lo que nació como ficción es ahora su verdadero mundo: "I felt like I was part of something there, you know, like in church, except it was more real than any church," (166). El exterior, la oficina, su compañero de trabajo Lou, el bar donde celebra las victorias de la UBA, la tienda de la esquina, son ilusiones, lugares de paso que ya no encuentran sitio ni en su memoria.

En ocasiones, la experiencia que Henry Waugh vive a través del juego se asemeja extraordinariamente a la de cualquier protagonista de una novela de ciencia-ficción. La sustitución de un espacio real por otro virtual, y la ausencia de un otro de carne y hueso son, como argumenta María Goicoechea, características fundamentales de este género:

Uno de los temas que recorre toda la colección es la lucha que se establece entre la búsqueda y necesidad del otro, frente al riesgo y la incomodidad que supone un contacto verdadero con él. El ciberespacio siempre es un sucedáneo, una antesala tras la que se espera una materialización física del otro para alcanzar el clímax de la narración. El rico mundo de relaciones generado en el ciberespacio contrasta con el

\footnotetext{
${ }^{16}$ Jean Baudrillard (2007).Cultura y Simulacro. Barcelona: Kairós.
} 
gran vacío de la vida fuera de él, poniendo de relieve la carencia de una fibra social compleja en la que el individuo pueda encontrar un anclaje. $(469)^{17}$

Estas mismas características podrían aplicarse a la obra que nos ocupa. Igual que los protagonistas de la literatura cyberpunk, el protagonista de The $U B A$, harto de la soledad y la rutina, se rodea de personajes imaginarios para disfrutar de una vida social de la que carece. Como un hacker enganchado al sistema o cualquier devoto usuario de la red, Henry se debate entre una vida mundana de oficinista o habitar para siempre en la fantasía. El contraste entre ambos tipos de vida es fatal y pronto se ve completamente absorbido por el encanto del juego.

Al fin y al cabo, Henry Waugh es el prototipo del fanático que vive por y para su afición. Coover ha querido retratar con benevolencia al individuo que utiliza un pasatiempo, en este caso un deporte, como vía de escape de una vida que nunca puede ser tan intensa como le gustaría. La novela es una caricatura del aficionado obsesivo, del fenómeno "fan" tan en boga en el último siglo. Pero también es la imagen especular del lector que reconoce en Henry o en cualquier seguidor férreo a una parte de sí mismo, la que quiere alejarse de la rutina y la banalidad a través de una obsesión.

Más aún si tenemos en cuenta que Henry no es un seguidor deportivo al uso, sino un jugador de un "Fantasy Sport", como son conocidas las recreaciones virtuales de los deportes. El "Fantasy Baseball" en concreto, nació en 1951 de la mano de Dick Seitz y se asemeja enormemente al juego creado por Waugh. Comenzó con un tablero y una lista de resultados asignados a las combinaciones de las tiradas de los dados. La versión más famosa y que más adeptos tiene es la del Strat-O-Matic, que ahora ha llegado también a la web, y que hace las delicias de cualquier aficionado al deporte que sueña con cambiar el rumbo del partido más importante de su vida o, simplemente, tomar el control de sus propios ídolos. La simulación del baseball es la materialización hiperreal del deporte, como, según Baudrillard, el saber se materializa en "información", los sueños en todos los Disneylandia del mundo, el espacio en el tránsito de las vacaciones, y el juego en la telemática privada ${ }^{18}$.

Las materializaciones son una forma de posesión de lo abstracto que simula un control sobre una sociedad altamente compleja y cambiante, donde los referentes y los mitos que la sustentaban han desaparecido y el sujeto, desorientado, trata de comprenderla y controlarla. $\mathrm{O}$ al menos, así parecen percibirla no sólo Coover, sino

17 Goicoechea, María (2004). El lector en el ciberespacio: Una etnografía literaria de la cibercultura. Tesis. Universidad Complutense de Madrid.

18 "[Las imágenes] se han convertido en nuestro auténtico objeto sexual, el objeto de nuestro deseo. $\mathrm{Y}$ en esta confusión de deseo y equivalente materializado en la imagen - no sólo deseo sexual, sino también deseo de saber y equivalente materializado en la "información", deseo de sueño y equivalente materializado en todos los Disneylandia del mundo, deseo de espacio y equivalente programado en el tránsito de las vacaciones, deseo de juego y equivalente programado en la telemática privada, etc.- reside la obscenidad de nuestra cultura". (Baudrillard, 1988: 30) 
también Barthelme, Gass o Delillo entre otros, pues sus personajes también sufren la incertidumbre y el hastío que les provoca el mundo en el que viven. Estos personajes, proyecciones del sujeto contemporáneo, se alejan de la realidad para observarla en la distancia y escapar así al aparente sinsentido de sus vidas.

Según los sociólogos Cohen y Taylor, las formas de evasión aumentan y se diversifican en proporción a la complejidad de la sociedad en que se habite. En una sociedad cambiante como la actual, el sujeto, desorientado, se aleja y la observa desde fuera. Nuestro protagonista, Henry Waugh, recurre al juego como vía de escape porque es un entorno donde se encuentra seguro, donde los límites son claros y las reglas siempre se cumplen: "Nothing like it really. Not the actual game so much - to tell the truth, real baseball bored him - but rather the records, the statistics, the peculiar balances between individual and team, offense and defense ... And no other activity in the world had so precise and comprehensive a history, so specific an ethic" (45). Es el espacio donde Henry encuentra sentido a su vida, donde todo está claro, perfectamente diseñado, a la vez que le proporciona la emoción que su aburrida vida de oficinista no le da.

En este sentido, el juego es un espacio de perfección, la perfección que nadie jamás podrá encontrar en el día a día, sino en un sistema diseñado a la medida de uno mismo. En palabras de Henry, simplemente "think what a wonderful rare thing it is to do something, no matter how small a thing, with absolute unqualified utterly unsurpassable perfection!" (23) Sin embargo, como afirma Baudrillard en El Crimen Perfecto, el verdadero crimen es la perfección, la conclusión, lo acabado. Los pueblos antiguos siempre trataban la ilusión con la ilusión, los sueños con los sueños. Los pueblos en la actualidad tratan de perfeccionar la realidad, reducirla a lo verdadero, y esa es la más grande ilusión. Los personajes de Coover, no sólo Henry, viven obsesionados con la perfección. Tiger Miller en The Origin of the Brunists dice: "they shared, that is, this hope for perfection, for final complete knowledge, and their different approach actually complemented each other, or at least seemed to" (Coover, 1965: 261). Pero la perfección para nuestro protagonista es una obsesión que lo aleja de los demás y, así, cuando piensa en enseñarle el juego a otra persona dice "Yet, damn it, somehow he felt jealous of that perfect game, felt an uncommonly strong wish to be alone this evening, and besides, Lou could spoil it" (51). Tal vez la neurosis de Henry y otros por la perfección sea, como afirma Baudrillard, una patología de nuestros pueblos, los cuales, al alcanzar metas insospechadas en tiempo récord no pueden esperar a ver el mundo a su medida. Lo que sí parece cierto es que "as we might expect of people who are seeking 'final complete knowledge' ends in a failure, just as all similar searches end in Coover's fiction" (McCaffery, 33). 


\section{VÍAS DE ESCAPE: LA HIPERREALIDAD COMO FORMA DE VIDA}

\begin{abstract}
En esto descubrieron treinta o cuarenta molinos de viento que hay en aquel campo; y así como don Quijote los vio, dijo a su escudero: - La ventura va guiando nuestras cosas mejor de lo que acertáramos a desear; porque ves allí, amigo Sancho Panza, donde se descubren treinta o pocos más desaforados gigantes, con quien pienso hacer batalla [...]-¿Qué gigantes? - dijo Sancho Panza.
\end{abstract}

(Miguel de Cervantes, El ingenioso hidalgo Don Quijote de la Mancha.)

La perfección que buscan Henry y Tiger Miller es la misma que la que ansían muchos otros personajes. Desde Alonso Quijano hasta el narrador de "Mrs. Mean" de W. H. Gass, todos anhelan lo mismo: un espacio acotado y a su medida. Un espacio que no encuentran en el mundo y deben crear ellos mismos. La evasión es la respuesta natural a una serie de circunstancias adversas para reafirmar la propia individualidad. De hecho, para Cohen y Taylor constituye una forma de construir la identidad. La búsqueda de aquello que nos hace únicos requiere un distanciamiento consciente de la realidad. Al mismo tiempo que nos consideramos miembros de distintas comunidades, deseamos diferenciarnos del resto, incluso de nuestros iguales. Además, "the contemporary individual is prey to a recurrent sense of disatisfaction. $\mathrm{He}$ is intermittently bored, frustrated and neurotic. Life is only occasionally there to be simply lived" (21). Para luchar contra el tedio y para redescubrir nuestra individualidad, nos distanciamos de la vida que nos ha tocado vivir y la miramos desde lejos. En la distancia y en la reflexión, creamos nuestra identidad y se podría decir, con Erving Goffman, que: "Our sense of being a person can come from being drawn into a wider social unit; our sense of selfhood can arise through the little ways in which we resist the pull." $(320)^{19}$ Henry Waugh encuentra lo que le hace único, la manera de "resistir el empujón" en su juego: "every inch of him a participant, maybe that was all it was; his total involvement, his oneness with the UBA" (9).

Evadirse se convierte así en una forma de redescubrimiento en una sociedad marcada por (8) la soledad y la ausencia del otro. Como apuntábamos en nuestra comparación entre The UBA y la literatura cyberpunk, Henry se debate entre la intensidad de una vida artificial imaginaria y la real, pero también entre "la necesidad del otro" y "la incomodidad que supone un contacto verdadero", porque sufre lo que Baudrillard denomina como la "ausencia del otro":

\footnotetext{
${ }^{19}$ Erving Goffman Assylums. New York: Anchor Books, 1961. (p.320) en Cohen y Taylor (p.23)
} 
La peor alienación no es ser desposeído por el otro, sino ser desposeído del otro: es tener que producir al otro en la ausencia del otro, y así continuamente ser devuelto a uno mismo y a la imagen de uno mismo. Si hoy estamos condenados a nuestra imagen (a cultivar nuestros cuerpos, nuestra apariencia, nuestra identidad, nuestros deseos), no es por culpa de la alienación, sino por culpa del fin de la alienación y de la desaparición virtual del otro, que es un destino mucho peor. (2000: 55)

Henry encarna el sujeto que, ante la ausencia del otro, debe producirlo. Él es el producto de una sociedad eminentemente solitaria pero materialmente rica, donde hay menos barreras entre objeto y sujeto que entre personas. "El hecho de preferir el ser virtual - el lejano - al ser real - el prójimo -, es preferir (o confundir) la figura, el clon, a un ser, un ser de carne y hueso que no comete otro error que el de estar aquí y ahora, y no allí." (Rial Ungaro, 44) ${ }^{20}$ La ausencia del otro, según Baudrillard, es una característica esencial de nuestro tiempo que se suple recuperando los signos del mismo pero desligados de su significado, un otro sin ontología, convertido en objeto, en un yo virtual, en un doble a la medida del sujeto creador: "los otros virtualmente ya no existen...Imaginar a los demás y todo cuanto nos acerca a ellos es inútil desde que la "comunicación" nos los vuelve inmediatamente presentes". (1988: 35-36) La distancia entre sujetos aumenta pero se acorta con los objetos que actúan de intermediarios. Rodeado de objetos pero cada vez más solo, el sujeto postmoderno se asemeja al loco propietario de la UBA.

En este sentido, la novela describe una incansable búsqueda de identidad a través de otro en la ausencia de éste. El momento del espejo es el resultado del desdoblamiento de la mirada, y de la simultánea conciencia de ver y ser visto, ser sujeto y objeto de la mirada de otro al mismo tiempo. Sin embargo, según Baudrillard, el otro ha desaparecido de nuestra sociedad y ha sido sustituido por una multitud de copias de uno mismo que no dejan espacio para la reflexión, sino que sólo lo absorben. No "hay sujeto, ya que la reduplicación de la identidad acaba con su división. La fase del espejo es abolida, o mejor, parodiada de una forma monstruosa" (1981: 159). El otro, por su distancia y por su propia alteridad, seduce e inquieta. El doble, por su parte, "asedia al sujeto como una muerte sutil" (1981: 157), y lo ahoga como a Narciso. Henry Waugh es este nuevo Narciso que debe crear sus propios dobles como sustitutos de los otros, lo que le mueve a evadirse hasta la autodestrucción.

Henry se convierte así en lo que Baudrillard denomina "sujeto fractal", quien:

en lugar de transcenderse en una finalidad o un conjunto que le supera, se difracta en una multitud de egos miniaturizados, absolutamente semejantes entre sí, que se desmultiplican embrionariamente ... saturando su entorno hasta el infinito. De la misma manera que el objeto fractal se asemeja en todos sus rasgos a sus componentes

\footnotetext{
${ }^{20}$ Santiago Rial Ungaro (2003). Paul Virilio y los limites de la velocidad. Móstoles (Madrid): Campo de Ideas.
} 
elementales, el sujeto fractal sólo sueña en parecerse a cada una de sus fracciones. (1988: 34).

Como el sujeto postmoderno que es, Henry sueña con parecerse a cada una de las imágenes idealizadas de sí mismo que ha proyectado con esmero y mimo en sus jugadores. "Henry... was Old Fennimore McCaffree in his Black suit giving orders and Barney Bancroft urging the boys how they had to win this game and all the old Elders... and the catcher Chauncey O'Shea... and Frosty Young..."(124). Su obsesión le impulsa a hacerse pasar por ellos, no sólo en la soledad de su hogar sino también (y muy especialmente) en situaciones embarazosas, como cuando se prepara para pasar la noche con una mujer:

"We're at your place", she said huskily when they'd got in there, and squeezed up against him. "Who are you now?" That she remembered! She was wonderful!

"The greatest pitcher in the history of baseball," he whispered. "Call me... Damon"(29).

Henry, absorto en su mundo hiperreal, es incapaz de afrontar el día a día solo, así que utiliza toda una serie de máscaras o falsos yoes para hacerlo. Según R.D. Laing, la proyección de dobles atiende a un intento por proteger el yo interno ${ }^{21}$, aunque suele producir el efecto contrario, pues impiden un contacto con el exterior y provocan que el yo interno se marchite. Cuanto más se difracta Waugh en estas imágenes, menos queda de sí mismo y la situación le conduce a la más absoluta locura. Expuesto a todas las imágenes a la vez, el sujeto postmoderno encarnado en Henry sufre del

terror característico del esquizofrénico - una excesiva proximidad de todo, una promiscuidad infecta de todo - ... Más que por la pérdida de lo real, se caracteriza por esta proximidad absoluta e instantaneidad total de las cosas, una sobreexposición a la transparencia del mundo. Despojado de toda escena y atravesado sin obstáculo, ya no puede producirse como espejo. (1988: 23)

\footnotetext{
${ }^{21}$ Según explica Carmen Méndez siguiendo a R. D. Laing, los dobles se crean como protección del yo interno: "Como defensa, el esquizofrénico ... Escinde su yo, dividiéndolo en varias partes: el yo interno ("inner self"), aislado del mundo, que considera como su "auténtico" yo y que por tanto desea proteger, y el yo externo o falso yo ("false self"); o incluso varios falsos yoes con distintas características que se usan de forma alternativa, que se emplean como máscaras para proteger el yo interno, encargándose de las relaciones con el otro y el mundo. Al mantener esta división interna, esta fachada de un falso yo que oculta el yo verdadero, éste último no interacciona con el exterior y la percepción e interacciones acaban siendo futiles, frente a lo que sucedería con un yo integrado, en el que la relación con el exterior y el otro tiene influencia no sólo en el yo, sino también en el exterior" (2005. Retórica de la esquizofrenia en los epígonos del modernismo. Tesis. Madrid: Universidad Complutense, p. 36)
} 
"Despojado de toda escena", de ese entorno social que haga del mundo un lugar donde vivir, Henry busca refugio fuera de él. Para hacer del juego una suerte de hogar, Waugh utiliza lo que Saler denomina la imaginación irónica, esto es, "a way to experience wonders and marvels while avoiding enchantment's potential to beguile" (139). No es que Henry evite por completo la posibilidad de verse atrapado por el encanto de su juego, pero sí que lo experimenta desde la racionalidad característica de nuestra época. Según Saler, puesto que ya no podemos creer a ciegas en los mitos y en las maravillas que hasta hace poco eran "reales" para el ser humano, y como él mismo y el propio Coover afirman, no podemos realmente vivir sin estas ficciones, el hombre contemporáneo las encara desde la racionalidad, siendo conscientes de que son meras invenciones. Henry, por ejemplo, sabe que "mostly he was only J. Henry Waugh, pooped and plastered Prop., thinking that this was sure a helluva thing for a grown man to be doing at dawn on a working day" (125), pero saberlo no le impide seguir, sino todo lo contrario: lo incorpora en su vida de manera totalmente consciente.

La "imaginación irónica" es, ante todo, una forma de recuperar el encanto del mundo premoderno de una manera aceptable para el público de una sociedad secular y racional. Una de las formas más comunes son las novelas de detectives, auténticos cuentos de hadas en los que el protagonista siempre alcanza su objetivo, pero nunca de manera inefable, sino gracias a la lógica y la ciencia, armas de la nueva sociedad moderna. A este respecto, la figura de Sherlock Holmes se ha convertido en auténtico tótem para aquellos que, como Henry Waugh, deciden emplear la imaginación irónica en sus vidas. Y es que él no es el único en "creer" en personajes ficticios sabiendo que son ficticios. Sherlock Holmes ha inspirado más biografías (cuidadosamente documentadas) que Sir Arthur Conan Doyle, y sus seguidores afirman "creer" en él, siendo plenamente conscientes de que no existe. Así nacieron la Baker Street Irregulars (EEUU) y The Sherlock Holmes Society (Reino Unido), cuyos miembros se reúnen y se disfrazan de los personajes para recrear al milímetro los casos del detective. Importantes personalidades han recurrido a esta comunidad para hacer realidad las asombrosas aventuras que leían ${ }^{22}$. Pura hiperrealidad que convierte al detective en algo más real que lo real. Como Henry, los miembros de estas sociedades

22 Para más información acerca de este curioso fenómeno, remitimos al interesante artículo de Michael Saler Modernity, Disenchantment, and the Ironic Imagination (v. Referencias), un breve recorrido por la historia de las recreaciones simuladas que buscan recuperar el "encanto" y la magia premodernos en la sociedad actual. Según el propio autor: "These late Victorian and Edwardian spectacular texts were the precursors of the internally consistent virtual worlds of our contemporary media, like Star Trek, Star Wars, and online computer gaming worlds, all of which have become imaginative habitations for millions. The first modern fantasy world to be inhabited this way by a community of fans was J. R. R. Tolkien's The Lord of the Rings. This was in part because the trilogy created a rationally coherent and realistically detailed "secondary world" through the use of maps, invented languages, and a meticulously conceived prehistory." (145) Mundos independientes y cada vez más realistas que se multiplican hoy en día y se perfeccionan en juegos de rol, videojuegos, juegos online, etc. 
adoptan la personalidad de los personajes, se comportan como ellos, y por unos momentos viven dentro de un universo particular alejado del mundo exterior. Autor y receptor son así cómplices del engaño mutuo de manera que "one could actively believe, albeit ironically, in marvels and wonders, without compromising one's standing as a rational and responsible adult." (Saler, 142) La imaginación irónica es exactamente lo que Henry pone en práctica en su juego. Al crear estadísticas y multitud de normas, con cifras e historiales perfectamente documentados, su juego adquiere una cierta seriedad que lo distingue de pasatiempos infantiles, un espacio aceptable para cualquier persona coherente. Como jugador "suspende su incredulidad" y acepta una mentira, pero como autor sabe que para creer esa mentira debe incorporar elementos pretendidamente racionales. Las normas y las reglas que se autoimpone no sólo dan realismo al juego, sino que lo alejan (en apariencia) de mitos y leyendas premodernos. Su creencia parece menos un acto de fe gracias a estos instrumentos. Pero lo cierto es que encerrarse en su casa a hablar con amigos imaginarios tiene tanto de irracional como la magia o la fantasía.

Con el tiempo, y sobre todo la disponibilidad de medios para hacerlo, comunidades como la de la Sherlock Holmes Society se han multiplicado. Así tenemos a los cosplayers, jóvenes (y no tan jóvenes) que se disfrazan de sus personajes favoritos del cómic para hacerlos realidad por unos momentos en convenciones y festivales dedicados a estas obras. Otros aprenden lenguas inventadas como el élfico y las hablan con devotos aficionados como ellos de El Señor de los Anillos. Y otros se reúnen anualmente en festivales dedicados íntegramente a la música y la estética del Rock de los años 50 y durante tres días levantan toda una ciudad a donde sólo se puede acceder si se va adecuadamente vestido/disfrazado. Estas tres comunidades son sólo algunas de las muchísimas que existen de este tipo y en la que podríamos incluir la que Henry crea. Son habitáculos imaginarios para una nueva sociedad que utiliza la ficción para sobrevivir a su existencia. Una sociedad en parte infantil que se refugia en paraísos idílicos y relatos catárticos para huir de las pequeñas frustraciones del día a día. Pero también una sociedad empujada a la evasión por la enorme afluencia de vías de escape que la conforman y que convierten a su población en una serie de fans solipsistas.

$\mathrm{La}$ "alucinación consensuada" que se pone en práctica cohesiona a sus miembros en una suerte de comunidad virtual. Las comunidades de cibernautas, por el interés que suscitan entre los académicos, son algunas de las más estudiadas y comparten con las ya mencionadas y con la UBA de Henry una serie de rasgos que las caracteriza como tales. Uno de ellos sería la "necesidad del otro" y "el miedo a un verdadero encuentro con él" que hemos comentado en páginas anteriores. De ahí que se utilicen disfraces, avatares, personalidades imaginarias, etc. para relacionarse. Por una parte, refuerzan la alucinación que cohesiona al grupo (pues los personajes elegidos suelen pertenecer a su universo) y, por otra, salvaguardan (en apariencia) la identidad propia. De esta forma se inicia un contacto con el otro, pero en un elemento seguro: el universo imaginado, el mito. Como en el caso de Henry, la evasión es utilizada para reafirmar una identidad. Así, al tiempo que se refuerza la individualidad, aquello que les hace únicos, se refuerza también la pertenencia a un 
grupo, la cara social. Además, es un espacio donde los límites entre ficción y realidad se diluyen y toda la teoría baudrillardiana sobre simulacro e hiperrealidad se hace patente. Los miembros de estos colectivos son los "Henrys" que se rodean de objetos e imágenes más reales que la realidad, hiperreales.

Henry Waugh no parece verse excesivamente afectado por la sociedad de ocio y consumo como lo están estos grupos, pero encarna el espíritu que les mueve a crear sus espacios hiperreales. Como decíamos unas páginas más atrás, Henry es el prototipo de la filosofía baudrillardiana en cuanto que revela la tendencia del hombre postmoderno a convertir las imágenes que lo rodean en simulacros, en hacer del objeto algo vivo para verse rodeado de una hiperrealidad en la ausencia del otro. A pequeña escala es una práctica que todos los habitantes de la sociedad de consumo llevamos a cabo cada día. Nos evadimos a través de la publicidad o de los medios a lugares cómodos, imaginarios y perfectos. Lugares que apelan continuamente al consumidor sin un segundo de descanso para prometerle el paraíso. Así, como afirman Cohen y Taylor

All around us - on advertisement hoardings, bookshelves, record covers, television screens - these miniature escape fantasies present themselves. This, it seems, is how we are destined to live, as split personalities in which the private life is disturbed by the promise of escape routes to other realities. (Escape Attempts, 139).

Los pequeños paraísos nos asedian y la vida se convierte en una suerte de esquizofrenia a medio camino entre lo soñado y lo vivido. La máxima expresión de dicha situación lo constituyen los grupos de aficionados que hemos mencionado y se refleja en los personajes postmodernos que, como Henry, manifiestan una cierta tendencia a aislarse de un mundo incomprensible para buscar refugio en habitáculos de orden y claridad, donde las normas que rigen los espacios míticos aseguran una felicidad sin límites. El deseo de hacer realidad lo inexistente hasta el extremo de "creer" en seres imaginarios convierte a todos ellos en el arquetipo de sujeto baudrillardiano absorbido por el simulacro. En sus mundos se hace patente que cada vez es más difícil distinguir ficción de realidad, entre otras cosas porque la técnica permite disolver estas barreras.

Aún hay un punto de interés que todavía no hemos comentado y que se pone de relieve en estos colectivos, esto es, la búsqueda de una comunidad. Estos grupos (y por ende la UBA de Henry) se convierten en comunidad en el momento en que desarrollan un habitus y se distinguen como colectivo del resto ${ }^{23}$. El habitus es todo vocabulario, comportamiento, normas y demás pautas que da sentido a una comunidad y que sus miembros deben dominar para formar parte de ella. En la UBA por ejemplo, tendríamos el rico vocabulario referido al baseball, las normas a seguir dentro y fuera del juego, los mitos y leyendas que comparten sus jugadores, el

${ }^{23}$ Nos referimos al concepto de habitus desarrollado por Pierre Bourdieu especialmente en obras como Razones prácticas: sobre la teoría de la acción (v. Referencias). 
comportamiento viril y jocoso que los caracteriza, etc. Gracias a estas pautas se desarrolla una identidad como miembro de un colectivo que los distingue de todos aquellos que no comparten el "habitus" y por tanto los diferencia como comunidad. En las novelas más conocidas de Coover como The Public Burning o The Origin of the Brunists la búsqueda de la comunidad es una constante. En The Origin of the Brunists, por ejemplo, la comunidad se crea en torno a la religión y en The Public Burning es a través del rechazo a un elemento común, el matrimonio de los Rosenberg. En general, las novelas de Coover suelen destacar por su carácter desmitificador y la necesidad de orden que sus personajes presentan frente a un mundo sin sentido, dos cualidades de la sociedad contemporánea que mueven a estos mismos a buscar un grupo de personas con las que tener algo en común. El aislamiento al que está sometido el sujeto actual no hace sino incrementar ese anhelo de una fibra social compleja que le permita establecer relaciones de manera natural. Las comunidades a las que nos hemos referido antes (fans de Sherlock Holmes, cosplayers, rockeros nostálgicos, y, sobre todo, cibernautas) ponen de relieve esta carencia, que no es sino una ausencia total de pautas comunes por las que regirse y la recuperación del mito en un mundo desmitificado. Las obras de Coover y de otros autores postmodernos insisten en esta cuestión a través de los sistemas artificiales que crean sus personajes. Los protagonistas de estas historias se rodean de personas (imaginarias y/o reales) con las que compartir algo que les una. No se trata solamente de tener compañía, sino de producir un entorno que al mismo tiempo que los acoja los diferencie del resto. En definitiva, cualquier tipo de contexto común que sirva de unión.

Esta búsqueda fehaciente de la comunidad no hace sino poner de manifiesto la ausencia de paradigmas sociales comunes. Al poner en entredicho los sistemas y pilares que conformaban la sociedad moderna y la mantenían cohesionada en torno a una serie de creencias, la postmodernidad se ha convertido en un período de crisis. No hay nada seguro, nada a lo que atenerse ni pauta alguna que seguir. Es la época de la deconstrucción, donde todo debe ser relativizado para alimentar el flujo y el intercambio e impedir la hegemonía de antiguos centros de poder para, simplemente, erigir otros. Como resultado, aparentemente aumentan la diversidad y la libertad para hacer desaparecer antiguas pautas y creencias comunes que mantenían a la sociedad unida. Para vivir en comunidad, esos elementos de cohesión (el habitus) deben estar presentes. Puesto que la sociedad no los brinda como forma de encuentro con el otro, grupos como los ya mencionados, y personajes como Henry o Daumier, deben crear los suyos.

\section{CONCLUSIÓN}

El relato sobre Henry Waugh nos sirve para sumergirnos en una realidad poco patente de nuestros días. Por una parte, es un relato sobre la evasión y la obsesión. Por otra, nos revela una serie de paradigmas a veces ensombrecidos sobre el mundo actual. Como hemos visto, existe cierto paralelismo entre las tesis de Baudrillard y la 
producción cultural actual. $\mathrm{Si}$ el individuo postmoderno vive asolado por simulaciones, Henry Waugh es el arquetipo de dicho sujeto. Rodeados por imágenes de un mundo mejor, de copias de la realidad como los "reality shows" y de dobles perfeccionados de uno mismo, los habitantes de la hiperralidad pierden sus referentes hasta ser incapaces de distinguir ficción de realidad. El mundo simulado sirve de modelo para el mundo real y lo simulado termina sustituyendo lo conocido como en The Universal Baseball Association, Inc., J. Henry Waugh, Proprietor.

Tal coyuntura no hubiera sido posible sin la proliferación de significantes sin significado en que se basa la sociedad de consumo. Este torbellino de objetos e imágenes da lugar a un entorno virtual que media con la realidad y, sobre todo, con los demás. En consecuencia, el contacto con el otro es cada vez menos directo y se ve mediado por el laberinto de signos que rodean al individuo. A través de Internet, la televisión o cualquier forma de mediación telemática, el otro se diluye y se transforma en un doble de sí mismo a la medida del sujeto receptor. Como el protagonista de The $U B A$, el sujeto postmoderno se debate entre el otro virtual y el otro físico.

Las obras cuya metaficción se cimenta en la simulación son la expresión de la hiperrealidad, la mímesis del simulacro. No es casualidad, por tanto, que los protagonistas de estas novelas se encuentren perdidos ante un contexto social artificial y vacío. En una época especialmente caótica y superficial, los personajes buscan rituales, organizaciones y juegos que les permiten evadirse y recuperar el control y la seguridad que un entorno en constante crisis no les proporciona. Ellos son el individuo dibujado por Lasch, Baudrillard y McCaffery, entre otros, que vive la realidad como si fuera una película, un juego, un programa o una novela; en definitiva, "ficcionalizándola" para soportarla y entenderla. Materialmente ricos y con todas las necesidades primarias cubiertas, no soportan lo trivial de su existencia y deben evadirse hacia lugares donde obtengan el afecto y el reconocimiento que no parecen encontrar en su vida.

Robert Coover profundiza en esta problemática abordándola desde la religión, el mito, el juego, la política, e incluso el espectáculo televisivo, entre otros. En The Universal Baseball Association, Inc., J. Henry Waugh, Proprietor, asistimos a la recreación de un orden hiperreal donde los signos de lo real sustituyen lo representado. Los jugadores de The Universal Baseball Association, como el individuo postmoderno, ya no encuentran significado a su existencia porque sólo les queda los signos de lo que fue el juego en sí. Puesto que esos signos refieren a algo anterior a ellos, mitifican el momento en que todo tenía sentido y se aferran a un discurso prestado. Los mitos son en sí mismos simulaciones y sobreviven hoy día del mismo modo que en la UBA, como un paisaje de referencias vacío. En la hiperrealidad del mundo extratextual, los referentes no sólo provienen de sistemas de creencia obsoletos, sino también del propio sistema de producción y consumo en que se basa el capitalismo. Los iconos, los referentes y los significantes vacíos, pues, se multiplican y parecen poseer el potencial para sustituir la realidad misma como el mapa que precede al territorio. Ésta es la coyuntura que plantea la novela al sustituir la realidad de Henry Waugh por la de su liga de baseball. Henry se convierte así en el 
arquetipo pesimista de la filosofía baudrillardiana sepultado por objetos y referentes vacíos, sin poder distinguir realidad de ficción porque vive en el orden de la hiperrealidad.

Pero no sólo se trata de dilucidar la naturaleza del entorno, sino también del ser humano. La sustitución del espacio real por otro virtual conlleva un distanciamiento del otro que, en ocasiones, hace preferir al ser imaginario frente al real. El otro pasa a ser una proyección, una imagen de sí mismo desdoblada, ubicua e instantánea, gracias al acortamiento espaciotemporal que los medios han propiciado. Al quedar reducido a una imagen, el otro se convierte en el doble del sujeto que lo percibe y pasa a formar parte de su solipsismo. Los otros, virtualmente, ya no existen porque la tecnología los convierte en figuras fantasmáticas. Son nuestros jugadores de baseball y el mundo nuestra UBA.

Ese mundo acotado y perfecto que se ha perseguido desde siempre y sólo podía quedar sublimado a través de la fantasía es en sí mismo una vía de escape. Vías de escape que se reproducen y que cimentan la sociedad del capitalismo tardío. Ahora estas fantasías cobran vida en la hiperrealidad y asolan al individuo como una red de mundos paralelos ideales que vienen a sustituir la tediosa realidad cotidiana. Si antes la evasión era una necesidad inherente al ser humano, ahora es casi una obligación, está presente en todas las facetas de la vida. La multiplicación y el perfeccionamiento de todas estas vías de escape vienen a confirmar, según Cohen y Taylor, la creciente necesidad del individuo por salvaguardar su identidad en una sociedad cada vez más compleja. Se convierten así en el limbo que el capitalismo tardío aprovecha para vender identidades prefabricadas que adoptar gracias al consumo de determinados productos. Sin embargo, en casos extremos como el presentado en la novela de Coover o en los grupos de fans, se trata principalmente de un espacio defensivo en el que desplegar una identidad alternativa al orden establecido. Esta situación es facilitada por la creciente ausencia del otro, por el aislamiento y la distancia que, por una parte, posibilita la evasión a través de un otro idealizado, y por otra incita a la búsqueda de una comunidad idílica. Las comunidades de cibernautas, cosplayers o fans de Sherlock Holmes revelan una creciente necesidad de escapar, una sofisticación de las formas de evasión y, sobre todo, el anhelo de una comunidad de la que formar parte. Las comunidades recreadas revelan también un regreso al mito y a la fantasía del mundo premoderno en un intento por simplificar su realidad y recuperar el encanto y la magia perdidos. Henry Waugh es el prototipo de ciudadano postmoderno atrapado por la soledad que crea, como ellos, una comunidad a su medida a través del mito y la fantasía.

\section{REFERENCIAS}

Augé, Marc (2006). Los "no lugares": espacios del anonimato : una antropología de la sobremodernidad. Barcelona: Gedisa,

Baudrillard, Jean (1979). Crítica de la economía política del signo. México: Siglo veintiuno. 
—— (1981) De la seducción. Madrid : Cátedra, D.L.1981

(1988). El otro por sí mismo. Barcelona: Anagrama.

- (2000) El Crimen Perfecto. Barcelona: Anagrama.

— (2000) Pantalla Total. Barcelona: Anagrama. (2007) Cultura y Simulacro. Barcelona: Kairós.

Benjamin, Walter (2003). La obra de arte en la época de su reproductibilidad técnica. México: Itaca.

Bourdieu, Pierre (1997). Razones prácticas: sobre la teoría de la acción. Barcelona: Anagrama, D.L.

Cervantes, Miguel de (1999). El ingenioso hidalgo Don Quijote de la Mancha. Madrid: Edaf, DL.

Cohen, Stanely H. y Taylor, Laurie (1978). Escape attempts : the theory and practice of resistance to everyday life. Harmondsworth : Penguin.

Coover, Robert (1965). The Origin of the Brunists. New York: G.P. Putnam's Sons.

- (1971). The Universal Baseball Association, Inc., J. Henry Waugh, Prop. New York: Plume.

Eco, Umberto (1999) Lector in fabula: la cooperación interpretativa en el texto narrativo. Barcelona: Lumen.

Engel, Stephen M (2004). Marketing Everyday Life: The Postmodern Commodity Aesthetic of Abercrombie \& Fitch. Advertising \& Society Review. Vol. 5, Número 3.

Goicoechea, María (2004). El lector en el ciberespacio: Una etnografia literaria de la cibercultura. Tesis. Madrid: Universidad Complutense.

Gordon, Lois (1983). Robert Coover: The Universal Fictionmaking Process. Carbondale: Southern Illinois University Press.

Jackson, Rosemary (1981). Fantasy: The Literature of Subversion. London: Routledge.

Laing R. D. (1961). The Divided Self. London: Tavistock.

Lasch, Christopher (1999). La cultura del narcisismo. Barcelona: Andrés Bello.

McCaffery, Larry (1982). The Metafictional Muse: The works of Robert Coover, Donald Barthelme and William H. Gass. Pittsburgh: University of Pittsburgh Press; London: Feffer and Simons.

McHale, Brian (1991). Postmodernist Fiction. London and New York: Routledge.

Méndez, Carmen (2005). Retórica de la esquizofrenia en los epígonos del modernismo. Tesis. Madrid: Universidad Complutense.

Palahniuk, Chuck (1997). Fight Club. London: Vintage.

Rial Ungaro, Santiago (2003). Paul Virilio y los límites de la velocidad. Móstoles (Madrid): Campo de Ideas.

Rubio Romero, Juana (2007). El consumo como configurador de identidades juveniles : una perspectiva sociohistórica y psicoanalítica. Tesis. Universidad Complutense de Madrid.

Saler, Michael T (2004). Modernity, Disenchantment, and the Ironic Imagination. Philosophy and Literature - Vol. 28, Número 1, Abril (137-149). 
Stoichita, Victor I. (2006). Simulacros: El efecto Pigmalión: de Ovidio a Hitchcock. Madrid: Siruela.

Todorov, Tzvetan (1995). Introducción a la literatura fantástica. México D. F.: Coyoacán. 